\title{
INOVASI TEKNOLOGI PLECING KALENG SEBAGAI PEMULIHAN EKONOMI PASCA GEMPA LOMBOK
}

\author{
Agung Prayogo ${ }^{1}$, Chadziqatun Najilatil Mazda ${ }^{2}$ \\ ${ }^{1,2}$ Universitas Proklamasi 45 Yogyakarta \\ email : agg.pry@gmail.com
}

\begin{abstract}
Abstrak : Lombok merupakan salah satu provinsi di Indonesia dengan banyak destinasi wisata. Pada bulan Agustus 2018 lalu, gempa berkekuatan 7 SR mengguncang destinasi pariwisata tersebut. Gempa Lombok menjadi sebuah ancaman wilayah bagi masyarakat dan turis asing maupun domestik. Akibat kejadian ini ialah ratusan orang mengalami luka-luka dan setidaknya 105 orang meninggal dunia. Gempa Lombok tidak hanya berdampak pada kerusakan bangunan dan fasilitas publik, namun juga pada sektor industri pariwisata yang berperan dalam peningkatan pertumbuhan ekonomi negara. Sektor ekonomi menjadi bagian yang paling terdampak secara signifikan. Sehingga, diperlukan suatu ide rekonsiliasi ekonomi pasca gempa Lombok. Salah satunya adalah melalui inovasi teknologi berupa pengalengan plecing kangkung yang merupakan salah satu makanan khas Lombok, terdiri dari Kangkung rebus dan disajikan dengan sambal tomat. Hasil penelitian menunjukkan bahwa inovasi teknologi pengalengan plecing kangkung mampu membuat jenis makanan ini lebih awet dan mudah dikonsumsi serta menjadi pilihan oleholeh untuk wisatawan domestik maupun asing Lombok. Melalui inovasi teknologi pengalengan plecing kangkung, diharapkan rekonsiliasi ekonomi masyarakat Lombok pasca gempa dengan memanfaatkan potensi lokal yang ada. Dengan demikian dalam jangka panjang turut serta sebagai solusi di bidang pariwisata berkelanjutan untuk daerah Lombok yang menjadi objek destinasi wisatawan.
\end{abstract}

Kata Kunci: Ekonomi, Gempa, Inovasi, Plecing Kaleng

\begin{abstract}
Lombok is one of the provinces in Indonesia with many tourist destinations. In August 2018, an earthquake measuring seven on the Richter Scale rocked the tourism destination. The Lombok earthquake has become a regional threat for the public and foreign and domestic tourists. As a result of this incident, hundreds of people were injured, and at least 105 people died. The Lombok earthquake had an impact on the damage to buildings and public facilities and on the tourism industry sector, which plays a role in increasing the country's economic growth. The financial industry is the most significantly affected. So, we need an idea of economic reconciliation after the Lombok earthquake. One of them is through technological innovation in the form of canning plecing kale, one of Lombok's special foods, consisting of boiled kale and served with tomato sauce. The results showed that the technological innovation of canning plecing kale could make this type of food more durable and easy to consume and a choice of souvenirs for Lombok domestic and foreign tourists. Through technological innovation of canning plecing kale, it is hoped that the economic reconciliation of the Lombok people after the earthquake by utilizing existing local potential. Thus, in the long term, participate as a solution in sustainable tourism for the Lombok area, an object of tourist destinations.
\end{abstract}

Keywords: Economy, Earthquake, innovation, Plecing kangkung

\section{PENDAHULUAN}

Pulau Lombok memiliki 2 generator gempa bumi, yaitu busur naik belakang flores dan megathrust sebagai zona subduksi atau penunjaman antara lempeng Australia dengan lempeng Eurasia. Garis Megathrust ini selain melewati Lombok juga melewati Barat Sumatera, Selatan Jawa, hingga ke arah Sumba dan berakhir di atas Maluku. Hal ini mengakibatkan gempa bumi menjadi suatu ancaman wilayah yang terjadi di Pulau Lombok.

Pada Seminar yang bertempat di Universitas Nahdlatul Ulama (UNU) Nusa Tenggara Barat pada Kamis 4 Juli 2019, Prof Ron Harris selaku pakar Geologi dan Kegempaan dari Brigham Young University menyampaikan hasil penelitiannya bahwa di Selatan Lombok terdapat potensi gempa berkekuatan 9 Magnitude. Menanggapi hal tersebut, Agus Riyanto selaku Kepala Badan Meteorologi Klimatologi dan Geofisika (BMKG) menghimbau masyarakat supaya tidak terlalu resah namun tetap waspada [1].

Badan Meteorologi Klimatologi dan Geofisika (BMKG) merupakan lembaga resmi yang menginformasikan akan terjadinya gempa bumi dan tsunami. Selanjutnya, Pada 9 Juli 2019 BMKG mengeluarkan Permakluman dengan Nomor: GF. 102/249/KMTR/VII/2019 guna menanggapi informasi yang beredar mengenai potensi gempa bumi dan tsunami di Selatan Lombok yang dimuat oleh Suara Lombok News. Dalam Permakluman tersebut disampaikan bahwa BMKG membenarkan 
informasi terkait potensi gempa bumi dan tsunami di Selatan Lombok, namun tidak dapat memprediksi kapan terjadinya. Sehingga masyarakat Nusa Tenggara Barat (NTB) dan sekitarnya diharapkan meningkatkan kesiapsiagaan dan kewaspadaan guna mengurangi resiko bencana [2].

Sebelumnya, Beberapa gempa bumi yang pernah mengguncang Lombok diantaranya terjadi di Kabupaten Lombok Utara pada Rabu 12 Juni 2019 pukul 02.51 WIB. Gempa tersebut berpusat di laut dengan kedalaman $12 \mathrm{~km}$, tepatnya di $36 \mathrm{~km}$ timur laut Kabupaten Lombok Utara dengan skala MMI III [3]. Gempa Bumi juga terjadi di Lombok Barat pada hari Selasa, 18 Juni 2019 pukul 20.50 WIB. Gempa tersebut berkekuatan magnitudo 2,8 dan berpusat di darat dengan kedalaman $19 \mathrm{~km}$, tepatnya berada di $14 \mathrm{~km}$ barat laut Lombok Barat. Getaran gempa ini juga dirasakan di Lombok Utara dengan Skala MMI II [4].

Salah satu gempa terdahsyat yang pernah mengguncang Lombok dalam kurun 2 tahun terakhir terjadi pada September 2018, dimana kerugian yang dialami terjadi karena berkurangnya minat di bidang pariwisata pasca gempa bumi yang juga berdampak pada perekonomian masyarakat Lombok. Dampak ekonomi pariwisata yang terjadi setelah bencana gempa bumi Lombok diperkirakan mencapai 100 juta US \$. Berdasarkan perhitungan dampak kerugian ekonomi pariwisatat tersebut, pihak Kementrian Pariwisata menyusun beberapa strategi pemulihan, yakni melalui pemulihan pada sumber daya manusia dan aktor pariwisata beserta instansinya, pemulihan destinasi tujuan wisata, serta pemulihan melalui strategi pemasaran baik pada segi branding advertising maupun selling.

Pemulihan pada aspek sumber daya manusia dilakukan melalui trauma healing kepada 1500 orang aktor pariwisata dan telah dilakukan di Sembalun, Trawangan serta destinasi objek wisata lainnya yang ada di Lombok [5]. Pada aspek pemasaran, dapat dilakukan dengan melakukan branding kembali, advertising, serta melalui selling. Kegiatan advertising difokuskan dengan memasarkan melalui pengiklanan destinasi pariwisata beserta layanan fasilitas rekreasi yang diberikan. Adapun aktivitas selling difokuskan pada penjualan baik itu cindera mata, maupun makanan kuliner sebagai oleh-oleh khas Lombok.

Makanan Kuliner selain menjadi kebutuhan primer masyarakat juga memiliki peran strategis dalam keterkaitannya dengan kemandirian dan inovasi pariwisata berkelanjutan. Plecing kangkung merupakan salah satu jenis makanan kuliner khas daerah Lombok yang perlu dikembangkan guna mendukung pemulihan ekonomi pasca bencana melalui selling atau penjualan.

Guna meningkatkan daya jual atau selling makanan plecing kangkung, maka inovasi teknologi diusulkan melalui aktivitas pengalengan makanan. Pengalengan makanan merupakan salah satu cara untuk mengawetkan bahan makanan maupun makanan jadi yang dikemas dengan rapat, sehingga tidak bisa dimasuki oleh air, udara dan mikroorganisme lainnya. Makanan kaleng memiliki karakter khas berupa konsistensi terhadap perubahan kadar air, perubahan rasa serta proses oksidasi yang mengakibatkan kebusukan makanan. Teknologi pengalengan makanan bisa diterapkan hampir ke seluruh variasi makanan dan minuman, daging, telur, sayuran hingga buah-buahan [6].

Penelitian sebelumnya telah dilakukan oleh Nurhikmat dengan studi kasus pengalengan pada gudeg. Hasil penelitian menunjukkan bahwa terdapat perpindahan panas pada saat proses sterilisasi gudeg kaleng dan dapat dituliskan ke sebuah pemodelan matematis. Pemodelan tersebut menggunakan tools software matlab versi R2010a. Hasil simulasi memperlihatkan semakin lama proses sterilisasi dan semakin tinggi suhu yang digunakan maka warna gudeg kaleng menjadi semakin gelap. Kondisi ideal sterilisasi gudeg kaleng diperoleh dengan suhu sterilisasi $121^{\circ} \mathrm{C}$ selama 20 menit [7].

Menurut penelitian Khusnayaini, implementasi teknologi dalam pengalengan makanan mampu meningkatkan kualitas dan daya tahan produk. Penerapan teknologi pengalengan makanan menggunakan suhu tinggi (lebih dari $100^{\circ} \mathrm{C}$ ) mampu memperlama masa penyimpanan gudeg serta menghambat proses pembusukan makanan. Makanan yang disimpan berhasil bertahan lebih dari 12 jam serta tetap menjaga kualitas produknya [8]. Tingkat sterilisasi makanan yang dihasilkan menunjukkan apakah proses sterilisasi yang dilakukan sudah cukup atau belum. Sehingga dibutuhkan perpaduan kombinasi suhu proses dan lama waktu yang tepat yang diperlukan untuk standarisasi keamanan dan menjaga kualitas produk yang dihasilkan.

Keberhasilan-keberhasilan penelitian sebelumnya terhadap gudeg kaleng telah menginspirasi penulis untuk melakukan penelitian terkait plecing Kaleng sebagai solusi yang 
ditawarkan dalam proses selling pasca bencana. Penerapan inovasi teknologi pembuatan plecing kaleng diharapkan mampu meningkatkan mutu dan keamanan dari produk plecing kangkung. Dimana plecing kaleng yang dihasilkan memiliki tingkat sterilisasi tinggi dari mikroba penyebab kebusukan serta memiliki masa simpan yang lebih panjang sehingga menjadi nilai tambah tersendiri untuk produk tersebut. Melalui inovasi ini diharapkan pula dapat membuka peluang usaha di bidang-bidang yang lain sebagai wujud dari unsur sustainable atau keberkelanjutan. Plcing Kaleng diharapkan melalui proses selling memiliki daya jual yang tinggi dan mampu menembus pasar internasional, yang pada akhirnya juga akan meningkatkan peulihan ekonomi pasca terjadi bencana di Lombok. Oleh karena itu, maka pada penelitian ini perlu dilakukan sebuah penyusunan konseptualisasi desain terhadap pengalengan Plecing Kangkung.

\section{LANDASAN TEORI} Plecing Kangkung

Plecing Kangkung merupakan makanan khas Indonesia yang berasal dari lombok. Makanan plecing kangkung terdiri atas sayur kangkung yang direbus dan disajikan dalam keadaan segar dengan sambal tomat plecing yang khas. Plecing kangkung biasa disajikan bersamaan dengan ayam taliwang dan tambahan sayuran seperti kacang panjang, tauge dan jenis urap lainnya. Secara umum, plecing kangkung terdiri atas beberapa bahan sebagai berikut:

Bahan :

- 200 gr kangkung segar

- $\quad 1 / 2$ sendok teh gula pasir

- 7 sendok makan minyak goreng

- 1 buah jeruk limau

- 1 sendok teh garam

Bumbu uleg halus :

- 2 siung bawang putih

- 4 butir bawang merah

- 1 buah cabe merah besar

- 10 buah cabe rawit merah

- 1 sendok makan terasi bakar

- 3 butir kemiri

Cara membuat plecing kangkung:

1. Pertama memotong tomat menjadi 4 bagian
2. Memasak air di panci untuk merebus kangkung

3. Memasak air di wajan. Ketika air di wajan sudah mulai mendidih, lalu memasukkan potongan tomat, cabai, bawang merah dan bawang putih.

4. Memasak bumbu-bumbu hingga air dalam wajan menyusut dan kulit tomat layu

5. Ketika air di panci sudah mulai mendidih, tambahkan garam secukupnya untuk menambah sedikit rasa pada kangkung serta menjaga warnanya agar tetap hijau.

6. Ketika bahan untuk bumbu halus sudah selesai direbus, selanjutnya menggerus bumbu tersebut dengan menambahkan terasi dan gula merah

7. Sambal plecing yang sudah jadi siap dipindahkan ke dalam mangkuk dan ditambahkan garam serta perasan air jeruk limau

8. Kangkung yang sudah matang diangkat dan ditiriskan serta dibelah-belah agar tidak menggumpal

9. Plecing kangkung disajikan diatas piring dengan menambahkan sambal plecing diatas kangkungnya.

\section{Teknologi Pengalengan}

Teknologi pengalengan (canning) merupakan salah satu teknik mengawetkan makanan dengan cara memanaskannya pada suhu tinggi. Proses pengawetan terjadi melalui pembunuhan bakteri pembusuk dan patogen oleh panas. Terdapat dua teknik pemanasan, yaitu pemanasan basah dan pemanasan kering. Proses pemanasan basah dinilai lebih efektif jika dibandingkan dengan pemanasan kering [9]. Definisi pengalengan tidak hanya terpaku pada kegiatan pengalengan tradisinonal yang menggunakan media kemasan kaleng, namun juga dapat dilakukan menggunakan media kemasan nonkaleng, misalnya kemasan plastik, etrapack, dlass jar, pouch dan lain-lain [10]. Meskipun pengalengan dapat dilakukan menggunakan beberapa media, terdapat karakteristik khusus yang harus dimiliki oleh wadah pengalengan, yaitu wadah harus tertutup rapat dan tidak dapat dimasuki oleh udara maupun bakteri pembusuk.

Proses pengalengan makanan dapat dilakukan melalui pasteurisasi dan sterilisasi komersial. Proses pasteurisasi lebih ditujukan untuk produk makanan dengan tingkat keasaman tinggi 
$(\mathrm{pH}<4.5)$ maupun produk makanan yang dilakukan menggunakan kombinasi dari metode pengawetan lain, misalnya melalui pendinginan ataupun menambahkan bahan pengawet. Adapun proses sterilisasi komersial diperuntukkan terhadap produk makanan dengan tingkat keasaman rendah $(\mathrm{pH}>4.5)$.

\section{Proses Pengalengan Makanan}

Proses pengalengan makanan secara umum dimulai dengan mempersiapan bahan yang akan dikalengkan, mengisi kaleng dengan makanan, mengisi medium, ekshausting, menutup kaleng, melakukan sterilisasi, melakukan pendinginan, dan terakhir adalah penyimpanan. Proses persiapan pengalengan makanan dilakukan dengan aktivitas pemilihan bahan-bahan yang akan dikalengkan, pencucian, pemotongan, serta pengolahan memasak terhadap bahan-bahan plecing kangkung lainnya.

Menurut Lopez, pencucian bahan dilakukan dengan tujuan untuk memisahkan bahan dari campuran bahan-bahan asing yang tidak diinginkan, seperti

debu kotoran, tanah, minyak dan sebagainya sehingga diharapkan bisa mengurangi jumlah mikroba patogen pada bahan yang akan disterilisasi [11].

Setelah melalui proses pencucian, dapat dilanjutkan dengan proses blansir yang merupakan salah satu tahap penting pada pengalengan makanan dan berpengaruh terhadap kualitas dari produk akhir secara keseluruhan [12]. Beberapa tujuan dari aktivitas blansir diantaranya adalah menginaktivasi enzim pada makanan, mengurangi jumlah mikroba pembusuk, serta melunakkan tekstur sayuran sehingga memudahkannya pada saat proses pengisian sayuran ke dalam wadah. Proses blansir juga berfungsi untuk mengeluarkan udara yang terdapat pada jaringan sayuran sehingga mengurangi reaksi oksidasi yang berdampak pada pembusukan makanan. Proses blansir juga membantu pembentukan headspace pada saat proses pengalengan makanan. Proses blansir dapat dilakukan dengan cara mencelupkan bahan ke dalam air mendidih selama kurang lebih 5-10 menit. Pada saat memasukkan bahan ke dalam kaleng harus memperhatikan headspace atau sisa ruangan dibagian atas kaleng setebal $1-2 \mathrm{~cm}$ dari permukaan kaleng.

Menurut Hayadi, jika kaleng diisi terlalu penuh maka akan mengakibatkan keleng menggembung sehingga penampilannya menjadi buruk [13]. Pemberian headspace dimaksudkan supaya kaleng dapat ditutup lebih rapat. Ketika terjadi pengembunan uap air dalam kaleng, tekanan headspace menjadi turun dan tekanan atmosfer di luar akan menekan tutup kaleng sehingga proses penutupan menjadi kuat. Ekshausting atau penghampaan udara ialah proses pengeluaran udara ke dalam kemasan untuk mengurangi tekanan yang ada di dalamnya ketika proses pemanasan berlangsung.

Pengalengan makanan diharuskan berada pada kondisi hampa udara, dimana kondisi tersebut mampu mengurangi peluang terjadinya kebocoran kaleng dan reaksi-reaksi oksidasi lainnya yang akan menurunkan kualitas produk. Suhu ruangan hampa udara tersebut adalah $80-90^{\circ} \mathrm{C}$ dan membutuhkan proses ekshausting yang berlangsung selama 8-10 menit.

Penutupan kaleng dilakukan setelah proses ekshausting, ketika suhu masih cukup tinggi. Proses ini dilakukan dengan menggabungkan badan kaleng dengan tutupnya (double seaming). Menurut Muchtadi (1995), terdapat dua aktivitas standar yang dilakukan pada saat penutupan kaleng. Aktivitas yang pertama ialah untuk membentuk atau menggulung secara bersamaan bagian tepi dari tutup kaleng dan badannya. Adapun aktivitas yang kedua ditujukan untuk meratakan gulungan yang dihasilkan dari aktivitas pertama [14].

Proses sterilisasi dilaksanakan secepat mungkin setelah kaleng ditutup. Apabila jeda waktu atau waktu tunggu (holding time) sterilisasi terlalu lama, maka akan meningkatkan jumlah mikroba awal sebelum dilakukannya sterilisasi. Hal ini mengakibatkan standarisasi proses sterilisasi yang sudah ditetapkan mungkin menjadi tidak dapat membunuh mikroba yang ditargetkan. Adapun standarisasi suhu sterilisasi yang digunakan ialah $121^{\circ} \mathrm{C}[15]$.

Setelah melalui proses sterilisasi, Plecing kaleng kemudian didinginkan menggunakan air dingin.

Pendinginan dilakukan hingga suhu air dalam media mencapai $38-40^{\circ} \mathrm{C}$ (Muchtadi 1995). Proses pendinginan dilakukan secepat mungkin setelah proses sterilisasi guna mencegah terjadinya overcooking dan pertumbuhan kembali mikroba, terutama bakteri termofilik.

\section{METODE PENELITIAN}


Penelitian ini dilakukan menggunakan metode deskriptpif kualitatif. Data penelitian diperoleh melalui wawancara dan studi literatur dari berbagai referensi dan jurnal-jurnal. Metode penelitian wawancara dimaksudkan untuk mendapatkan informasi dari pakar tentang kondisi di wilayah Lombok pasca bencana. Adapun studi literatur dilakukan dengan maksud untuk mendapatkan informasi-informasi pendukung serta membentuk suatu konseptualisasi desain dari plecing kaleng yang akan dibuat.

Diagram alir penelitian digambarkan sebagai berikut:

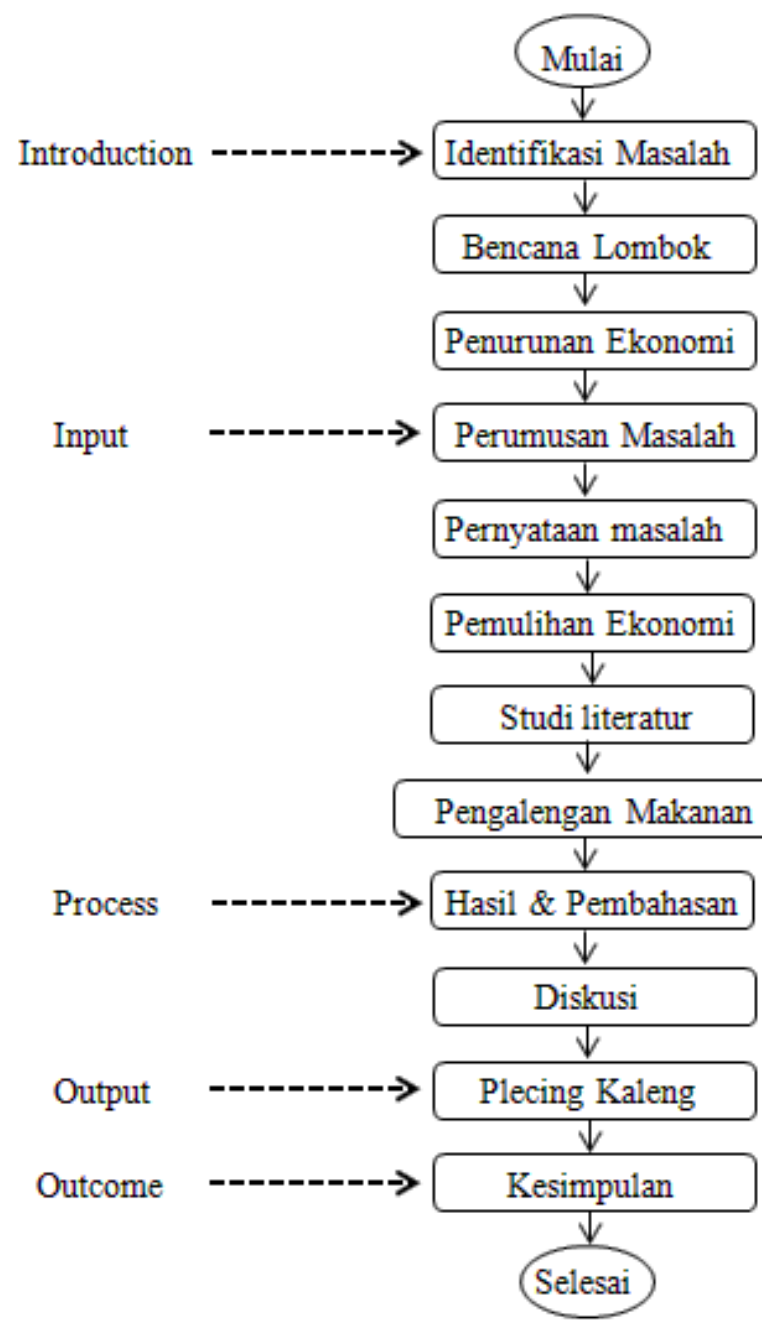

Gambar 1. Diagram Alir Penelitian

\section{HASIL DAN PEMBAHASAN}

Melalui pengumuman dari BMKG masyarakat Lombok dihimbau untuk meningkatkan kesadarannya terkait bencana. Hal ini karena Lombok merupakan salah satu wilayah di Indonesia yang rawan terhadap bencana. Masyarakat Lombok diharapkan kedepan lebih mandiri dan tangguh dalam menghadapi potensi bencana yang terjadi. Kemandirian masyarakat dapat diwujudkan melalui upaya persiapan mitigasi dan adaptasi terhadap bencana. Selain menyiapkan kemandirian terhadap kemungkinan terjadinya bencana, kemandirian juga harus diwujudkan melalui upaya persiapan pemulihan ekonomi pasca bencana, yakni dengan menyusun sistem perekonomian masyarakat yang kuat.

Penguatan ekonomi masyarakat dilakukan melalui sebuah inovasi teknologi yang berkelanjutan. Dimana melalui inovasi teknologi tersebut diharapkan tidak hanya berlangsung untuk jangka pendek, namun juga dapat diterapkan untuk jangka panjang. Selain itu, pemanfaatan inovasi teknologi juga harus memberikan multiplier effect terhadap bidang-bidang yang lain. Dimana melalui terciptanya inovasi tersebut mampu memberikan efek berupa penyerapan tenaga kerja baru, peningkatan permintaan kangkung dan bahan-bahan pembuat plecing lainnya, pepeningkatan permintaan terhadap kaleng kemasan di supplier, penambahan jaringan distribusi baru, penambahan varian makanan, serta penambahan ketertarikan minat konsumen untuk mengkonsumsi plecing kangkung dan membawanya sebagai oleh-oleh khas Lombok.

Teknologi pengalengan bukan merupakan sebuah teknologi baru. Teknologi pengalengan dimulai oleh Nicolas Appert pada tahun 1809 di Perancis. Adapun desain kemasan logam yang bisa dipatri dan dikomersialkan dipatenkan pada tahun 1810 oleh Peter Durant (Davis, 1967; Page et al., 2003). Selanjutnya pada tahun 1960 mulai dikembangkan kaleng jenis two piece serta diikuti dengan pengembangan tutup ring pull up untuk memudahkan pembukaan kaleng tanpa menggunakan alat (Page et al., 2003).

Melalui pengalengan plecing kangkung, diharapkan dapat berlangsung secara berkelanjutan. Dimana plecing kangkung yang biasanya hanya bertahan selama 12 jam, melalui inovasi ini plecing dapat bertahan lebih lama, dan dapat dinikmati oleh masyarakat luar Lombok. 
Proses pengalengan Plecing Kangkung secara umum adalah sebagai berikut:

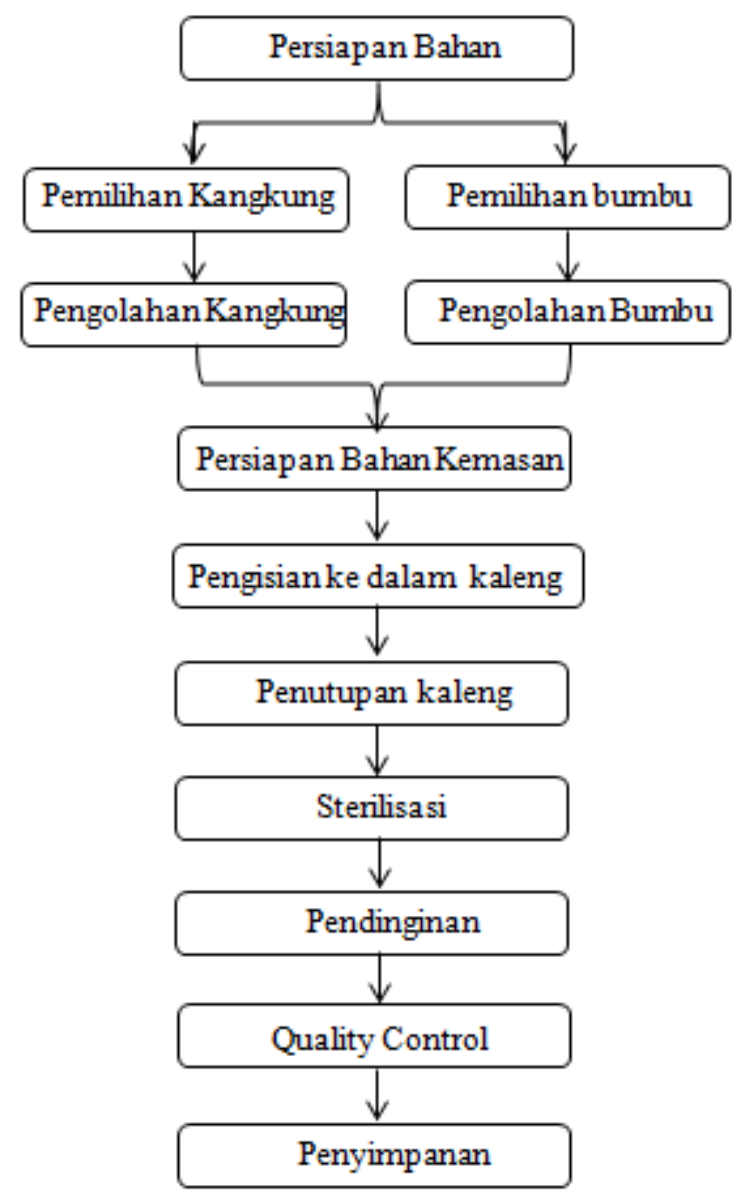

Gambar 2. Diagram alir plecing kaleng

Selama proses pengalengan, semua aktivitas harus dilaksanakan secara berkelanjutan dan tidak terputus. Jika terdapat proses pengalengan yang tidak dilanjutkan, maka dikhawatirkan hal tersebut dapat memberi kesempatan kepada mikroba patogen untuk masuk dan menyebabkan kebusukan. Secara umum, pengalengan Plecing Kangkung terdiri atas dua unsur, yaitu unsur isi (Kangkung dan Bumbu) serta unsur kulit (kemasan). Pada proses pengolahan isi dan pengalengan plecing kangkung tersebut terdapat beberapa tahap yang harus diperhatikan. Tahap-tahap tersebut antara lain sebagai berikut:

\section{a. Tahap Persiapan Isi Kemasan}

Isi plecing kaleng tidak lain berupa kangkung rebus yang diawetkan beserta bumbu halus plecing yang disimpan dalam wadah khusus sebelum dimasukkan ke dalam kaleng. Kangkung yang dipilih merupakan kangkung hijau segar jenis. Kangkung kemudian dibersihkan dan dimasukkan ke dalam exhaust berbentuk persegi panjang dengan conveyor yang panjang di dalamnya pada tahap perebusan awal (setengah matang). Adapun persiapan bumbu plecing dilakukan dengan memilih bumbu-bumbu terdiri atas cabai, tomat, bawang merah, bawang putih, terasi, garam dan bumbu halus lainnya. Semua bumbu digiling dan ditambahkan ekstrak jeruk limau serta bahan pengawet. Kangkung rebus dan bumbu yang sudah jadi akan menunggu untuk proses selanjutnya.

\section{b. Tahap Persiapan Bahan Kemasan}

Secara komersial, standar pengalengan Plecing Kangkung sangat tinggi. Selain memperhatikan kualitas bahan, perlu diperhatikan pula jenis bahan yang akan digunakan. Jenis bahan haruslah mampu menghantarkan panas dengan baik serta tahan terhadap panas agar tidak terjadi kebocoran. Hal ini dimaksudkan untuk mengantisipasi kecerobohan dan kesalahan selama proses pengerjaan kaleng kemasan selama pengolahan maupun penyimpanan. Jika pemilihan bahan kemasan kurang tepat, hal tersebut dapat menyebabkan kebocoran baik yang terjadi selama pemanasan maupun sesudahnya.

Setelah menentukan bahan kemasan kaleng yang tepat, langkah selanjutnya adalah memperlakukan kaleng tersebut dengan tepat. Penanganan kaleng secara kasar mampu menyebabkan kebocoran kaleng. Selain itu, kesempurnaan bentuk kaleng juga perlu diperhatikan. Hal ini karena adanya tonjolan pada permukaan maupun mulut kaleng yang bersinggungan dengan tutup kaleng dapat mengakibatkan ketidaksempurnaan proses penutupan sehingga memicu terjadinya kebocoran. Bahan kemasan untuk pengalengan makanan diharuskan mempunyai kekuatan mekanik yang tinggi, barrier yang baik terhadap gas, uap air, jasad renik, debu dan kotoran, toksisitasnya relatif rendah meskipun ada kemungkinan migrasi unsur logam ke bahan yang dikemas, tahan terhadap perubahan suhu yang ekstrim serta mempunyai permukaan yang ideal untuk dekorasi dan pelabelan. 


\section{c. Tahap Pengisian}

Saat memasuki proses pengisian, bumbu plecing kangkung terlebih dahulu dikemas ke dalam sebuah plastik dengan bantuan mesin dan di press dengan rapat. Setiap kemasan 1 plastik berisi bumbu plecing dengan berat 50 gram. Adapun kangkung yang sudah direbus, dikeringkan dan dipress terlebih dahulu untuk mengurangi kadar air yang tersisa. Kangkung rebus yang sudah dipress dan tidak mengandung banyak air kemudian dimasukkan ke dalam kaleng dengan porsi 300 gram. Diatas kangkung rebus kemudian ditambahkan bumbu plecing kaleng yang sudah dikemas.

\section{d. Tahap penutupan Kaleng}

Setelah pengisian selesai dilakukan, Hal penting lainnya yang perlu diperhatikan pada saat penutupan kaleng adalah untuk selalu mengantisipasi adanya kemungkinan bakteri masuk kembali dan mencemari plecing kangkung yang telah di sterilisasi. Oleh karena itu diperlukan suatu integritas sambungan dan penutupan kaleng sebagai faktor penting. Proses penutupan kaleng dilakukan dengan bantuan permesinan, dimana kaleng yang sudah terisi kangkung dan bumbu berada pada conveyor berjalan, kemudian dipress dengan tutup kaleng saat akan melewati ujung dari conveyor. Kaleng yang sudah tertutup akan dikumpulkan untuk memasuki tahap sterilisasi.

\section{e. Tahap Sterilisasi}

Tahap sterilisasi dilakukan dengan memberi perlakuan panas terhadap plecing kaleng yang sudah ditutup diatas retort dengan suhu $120^{\circ} \mathrm{C}$. Sterilisasi dimaksudkan untuk membunuh mikroorganisme patogen penyebab kebusukan pada makanan serta mengurangi kadar air yang masih ada pada kangkung dan bumbu plecing. Pada tahap ini, tinggi suhu yang stabil dan pemeriksaan alat pengangkutan kaleng menuju retort sterilisasi harus diperiksa secara periodik untuk memastikan kelancaran proses dan tidak merusak kemasan kaleng.

\section{f. Tahap Pendinginan}

Setelah melalui sterilisasi, tahap selanjutnya adalah pendinginan atau kondensasi. Pada tahap ini perlu dibuatkan prosedur standar untuk membakukan prosesnya, serta mengatur perubahan suhu dari panas ke dingin supaya tidak terlalu mencolok. Pada tahap pendinginan harus dilakukan dengan tepat untuk memastikan tidak ada uap air yang tersisa dan mengembun menetes di dalam kaleng.

\section{g. Quality Control}

Setelah dilakukan pendinginan, plecing kaleng mendapat perlakuan quality control untuk menjamin kualitas produk yang dihasilkan. Penilaian quality control dilakukan untuk melihat apakah ada kerusakan maupun perubahan pada produk akhir yang dihasilkan. Dalam hal ini, standar quality control yang diusulkan adalah menggunakan xxxxx. Adapun jenis kerusakan yang dimaksud seperti kaleng penyok, perubahan pada warna kemasan, terdapat kontaminan maupun terdapat produk yang memiliki berat kurang jauh dari rata-rata. Produk yang lolos quality control akan dilanjutkan ke penyimpanan dan penjualan.

\section{h. Penyimpanan}

Sebelum plecing kaleng yang sudah jadi disimpan, yang perlu diperhatikan adalah kebersihan ruangan serta plecing kaleng itu sendiri. Plecing Kaleng yang sudah jadi harus disimpan dalam keadaan kering. Kaleng yang disimpan dalam keadaan basah dapat memicu reaksi oksidasi sehingga berdampak pada pengkaratan. Adapun kebersihan ruangan mengharuskan suhu ruang yang tidak lebih dari $30^{\circ} \mathrm{C}$. Apabila suhu ruang terlalu panas, maka dikhawatirkan menimbulkan reaksi kimia pada bahan-bahan plecing sehingga berpengaruh terhadap perubahan rasa, warna, bau dan kualitas.

\section{KESIMPULAN DAN SARAN}

\section{Kesimpulan}

Lombok merupakan salah satu wilayah di Indonesai yang menjadi bagian dari bertemunya lempeng Australia dengan Lempeng Eurasia. Hal ini merupakan salah satu ancaman wilayah dan mengakibatkan Lombok menjadi daerah yang rawan terhadap gempa bumi. Dampak dari bencana tersebut adalah menurutnya ekonomi pariwisata di Lombok sehingga memerlukan strategi pemulihan, diantaranya melalui trauma healling, advertising dan selling. Pada aktivitas selling, dapat dilakukan melalui proses pengalengan plecing kangkung merupakan salah satu inovasi teknologi yang dapat diterapkan di wilayah Lombok. Melalui inovasi ini, diharapkan mampu meningkatkan ekonomi pariwisata di Lombok sehingga menjadi bagian dari pembangunan berkelanjutan disana. Saran yang dapat penulis berikan adalah adanya penelitian lebih lanjut mengenai time study untuk menentukan waktu standar dan waktu ideal dari pengalengan plecing kangkung. 


\section{Saran}

Penelitian ini memberikan ide terkait inovasi teknologi bidang pengalengan makanan, sehingga disarankan peneliti selanjutnya dapat mengkaji lebih detail terkait teknis aspek gizi yang ada pada plecing kaleng.

\section{DAFTAR PUSTAKA}

[1] Khalid, I., oleh editor Assifa, F., 5 Juli 2019, Garagara seminar soal gempa, warga NTB resah seharian, BMKG angkat bicara, https://regional.kompas.com/read/2019/07/05/0458000 1/gara-gara-seminar-soal-gempa-warga-ntb-resahseharian-bmkg-angkat-bicara

[2]Amani, M., oleh editor Wedhaswary, I. D., 9 Juli 2019, Beredar Surat Potensi Gempa Bumi dan Tsunami di Lombok, Ini Penjelasan BMKG. https://nasional.kompas.com/read/2019/07/09/171737 31/beredar-surat-potensi-gempa-bumi-dan-tsunami-dilombok-ini-penjelasan-bmkg

[3]Pribadi, M. A., Rabu 12 Juni 2019 Breaking News: Dini Hari Ini Lombok Utara Diguncang Gempa Bumi Berkekuatan sedang. https://wartakota.tribunnews.com/2019/06/12/breaking -news-dini-hari-ini-lombok-utara-diguncang-gempabumi-berkekuatan-sedang

[4]Daniswara, W., oleh editor Daryono, 18 Juni 2019, Gempa Hari Ini- Gempa Kembali Guncang Lombok Barat, Dirasakan Hingga Lombok Utara. https://www.tribunnews.com/regional/2019/06/18/gem pa-hari-ini-gempa-kembali-guncang-lombok-baratdirasakan-hingga-lombok-utara

[5]Nukman, H., 16 September 2018. Dampak Gempa Lombok, Sektor Pariwisata Alami Kerugian Besar. https://travel.detik.com/travel-news/d4214277/dampak-gempa-lombok-sektor-pariwisataalami-kerugian-besar

[6] Larousse, J. dan Brown, B.E., 1997, Food Canning Technology, Wiley VCH, New York.

[7]Nurhikmat A, Susanto A, Rahayu E. 2009. Penentuan Nilai Fo Gudeg Kaleng (Ukuran 301x205) dengan Perbedaan Letak Kaleng pada Tahap Sterilisasi. Yogyakarta.

[8]Kim, J., Foegeding, P. M., 1999, Principles of Control. In : Hauschild AHW dan Dodds KL (ed). Clostridium botulinum Ecology and Control in Foods. New York: Marcel Dekker Inc.

[9] Hariyadi, P., 2000, Pengolahan Pangan dengan Suhu Tinggi. In: Hariyadi P (ed). Dasar-dasar Teori dan Praktek Proses Termal. Bogor: Pusat Studi Pangan dan Gizi, Institut Pertanian Bogor.

[10] Lopez, A., 1981, A Complete Course in Canning. The Canning Trade Inc. Maryland.

[11]Ramaswamy, H. S., 2005, Thermal Processing of Fruits. In: In Barret DM, Somogyi L, Ramaswamy H.
Processing Fruits: Science and Technology. Boca Raton, London, New York, Washington D.C.: CRC Press.

[12]Muchtadi, D., Astawan, M., Palupi, N.S., 2006, Materi Pokok Metabolisme Zat Gizi Pangan. Universitas Terbuka, Jakarta.

[13]Hariyadi, P., Kusnandar, F., dan Wulandari, N., 2006, Teknologi Pengalengan Pangan. Departemen Ilmu dan Teknologi Pangan, Institut Pertanian Bogor. Bogor.

[14]Muchtadi, T. R., 1981. Pengaruh Penyimpanan Beku terhadap Mutu Daging Buah Nangka, Tesis, Program Pascasarjana, Institut Pertanian Bogor. Bogor.

[15] Widodo, P.P., Handayanto, R.T., dan Herlawati, 2013, Penerapan Data Mining dengan MATLAB, Rekayasa Sains, Bandung. 